\title{
An Overview of Basic Beliefs and Totalitarian Political Applications Related to Generics
}

\author{
Zitong Qiu, ${ }^{1, *}$ \\ ${ }^{1}$ Chengdu No.7 high school international department, Chengdu,Sichuan, China \\ *Corresponding author.Email:zitongqiu.p@foxmail.com
}

\begin{abstract}
Generics are summary statements like "sharks eat people" or "Black people are able to run very fast". By studying generics, people can understand the effects of language. Generics play a crucial role in people's minds. This thesis mainly discusses some theories about generics: Leslie's theory about generics and Haslanger's theory, giving an analysis of them. By using the way of case analysis and logical deduction, the author concludes three beliefs: the belief in the law of existence, the belief in the law of perdurability and universality and the belief in human's ability to analyze phenomena which people will hold when they are concluding phenomena into generics. Besides, by studying the case of the Nazi, the author concludes that by using generics, the government naturally owns the authority to control people's behavior, concluding that in order to avoid negative effects caused by the use of political generics, people must first notice that there is no so-called good or bad attributes only belong to one or more groups. All the people's attributes are developing instead of fixed. People also need to notice that some phenomena they observe do not have the authority for them to conclude a generic, since it's possible for the government to deliberately provide some special phenomena in order to achieve its own purpose.
\end{abstract}

Keywords: Linguistics, Generics, Totalitarian

\section{INTRODUCTION}

In order to understand today's society, one thing people must consider first is the influence of the use of generics. Generally speaking, the generics is like a summary. People often use it like sentences. For example, "sharks eat people" or "Black people are able to run very fast".[1] Generics has played a non-negligible role in creating people's thoughts and even prejudice. Thus, clearly studying and stating what makes generics come true becomes crucial for linguisticians. Leslie, S. J. developed her own theory about how generics affect people's minds. Haslanger constructed her own system about the relationship between language, social reality and material effects. However, what actually plays a role when people are concluding phenomena into generics? This research will give its own analysis to it. Also, generics without doubt can influence people's minds. Therefore, clearly study how government uses the generics to guide people's behavior becomes an interesting topic. Lyotard is one of the most famous philosophers who combine language with politics. This research will also cite his theory, talking about the relationship between generics and politics. In the first part of this thesis, the research will introduce the causes and the effects of generics, giving a summary of Leslie's theory. In addition to this, the research will give author's opinion about this theory and share the author's understanding of generics. Then, summarize Sally Haslanger's theory about the relationship between language, social reality and material effects. In addition, according to this, the research concludes the origin of some totalitarian state's authority, giving an example of this. At the end of this thesis, the research will talk about some ways to avoid some negative effects caused by the use of generics. Only when people notice the significant effects which caused by language can they be more rational and gain their own liberty. This research studies the process which creates generics, hoping the readers can notice this process when they are observing the phenomena. By doing this, people will create less prejudice any groups in the world. This research also warns people that if they ignore political generics, they will lose their liberty. If this research can help people to truly understand how irrational the prejudice is and how government gains its authority to control people, the objective of this research is achieved. 


\section{THE BELIEFS PEOPLE DEPEND ON FOR CREATING GENERICS}

In her thesis "Carving up the social world", Leslie expresses her opinion about generics. Generics are words that express cognitively basic generalizations. They reflect people's thinking about an object's essence. One feature of generics is their simpleness. It seems that it's easy for generics to be accepted by children. Thus, children can easily learn things from generics.[2] According to this, one can come up with an idea about the origin of generics, which is, the existence of generics enables humans to keep away from dangers. For instance, a person who believes lions attack humans" will understand the importance of not approaching a lion. Although lions do not always attack humans, it's undeniable that if they actually do such things, humans would be in great danger. From this perspective, it might seem that generics are created to help humans to live longer. It seems to be a rational answer to the origin of generics. Base on this theory, it seems that there are some "human properties" for us to discover.

\section{Phenomena - ?- Generics}

Figure 1 : How phenomena become generics?

According to figure one, the question mark illustrates the missing part in the process of forming generics. From a biological perspective, we can conclude that humans use generics in order to avoid dangers. Nevertheless, the research thinks we still lack a deep analysis to discuss what actually makes this process happen. Like the graph above, the question mark illustrates the part which people ignore when they are creating generics. Actually, Phenomena do not naturally form a generic. In fact, people are depending on some beliefs which make phenomena become a generic. what we know now is that when humans see some phenomena, they will then conclude a law or property to summarize these phenomena. A law or a property in here is like a generic. Nevertheless, the question is "what makes this come true?". There might be some basic beliefs humans follow when they conclude a generic. If we successfully solve this question, we can even figure out the nature of humans. For now, the research can only give some simple analysis of this. The analysis is as follows.

There are mainly three human basic beliefs which make the use of generics come true [10] .

First, it seems that when a person receives a number of phenomena, what the person holds is that he or she can actually find a kind of law inside an ocean of phenomena. Therefore, it can be concluded that the principle 1 the people hold when they are analyzing phenomena. That is the belief in the law of existence.

Second, this person might also believe that the law they find is perpetual (by perpetual the author means people believe this law can last very long that they can follow when they are arranging plenty of phenomena. Although Immanuel Kant clearly points out that the acquired synthetic judgement does not have universality and inevitability, people still use generics as their guide, so the author still considers this belief as a nature of humans). It's very possible that the law people conclude is wrong, but after this, what humans do is try to improve the law, making it adapt to phenomena they receive, instead of thinking about "the way which humans use to come up with a law" is wrong or "there is no such a property or law exist." As a result, it can be simplified as principle 2: The belief in the law of perdurability and universality

Third, humans might also believe in their ability to solve and analyze the phenomena they observe. (This kind of ability we could define as rationality which includes the law of causation or something like it). This belief comes naturally since it is the way we use to consider and analyze all the information. Humans can never think in a different way than this. It needs to be pointed out that it is possible for people to question the first and the second belief. Since they are not so solid. Nonetheless, people can never question the third belief, that is because when people are questioning the third belief, they are using the rationality itself [9]. So, the principle 3 is also clear, that is: The belief in human's ability to analyze phenomena.

\section{THE APPLIANCE OF GENERICS IN POLITICS}

Jud Süss is a film which Nazi used to show their people how evil the Jewish people are. The German propaganda Ministry ordered the director of the movie to reinforce racial differences in this movie[6]. The hero Suss was a jew. He was described as a mean and selfish capitalist who harms the racial purity of Germany during that time. Actually, Suss was just a rich people during that time. The successful point of this film is that it changes viewers' focus from the conflict between capitalists and the poor to races, or the conflict between Jewish people and so-called pure Germanic[7]. By producing movies like this, the government has created some phenomena for people to create generics. The German people will then blame Jews for problems that were in fact created by capitalists. And thus to generalize some of the attributes that were originally non-racial as being intrinsic to the Jewish people. When an ocean of generics was created by movies of propaganda, the social reality was created. As a result, the disaster happened. 
From this example, the research conducts an analysis. According to Leslie[1], one of the major effects of generics is prejudice. People in our world keep giving things around their properties. Some are negative and some are positive. However, all of them in my idea can be defined as prejudice. That is because human's existence proceeds essence [3] People before experience believe that there is a group of people who have some properties. For example, people in China often believe that people in India are unhygienic. This belief does actually harm people often. Thus, what is the relationship between language, social reality and the material effects caused by generics? Sally Haslanger gives her answer[4], which is, language in some ways creates social reality, and it creates material effects. In addition, then, the material effect in terms creates language. As this theory suggests, these three factors do not have a clear order. A better way to describe it is that they are actually like a loop. In this theory, for me, the most interesting part is that social reality can actually change human behavior[8]. For example, in a society in which people believe women are good at cooking, women who live there can be good at it. That is because women will believe that in order to be a better women, they must know how to cook well. By contrast, men in this society are probably not good at cooking at all. Since people will think it's right for men not to cook or "cooking is a woman's job, men who do it are not real men." This theory actually suggests that there is no so-called human nature that can predict human behavior, and it's possible for someone to change people's behavior by using language. According to this view, it's possible to understand the origin of a totalitarian state's authority. According to Jean-Francois Lyotard[5], these totalitarian states have a Grand Narrative, which means, a polity has a grand objective. Thus, in order to achieve this objective, some governments have the authority to guide people. By using language, governments, therefore own the power to guide their people, giving certain acts legality or illegality[10]. Generally, if humans can be affected by generics, it will give the possibility and authority to the government to control people.

\section{THE WAYS TO AVOID NEGATIVE EFFECTS CAUSED BY GENERICS}

Without a doubt, people in the world tend to create generics for them to use. However, in order to avoid negative effects (like the world war II) When people are analyzing the phenomena, they should realize that it's very possible that there is no so-called property or law hide behind these phenomena. People are often too confident about the generics they found by themselves, causing prejudice. The research, however, must point out that Blind confidence can only lead to sad results. When someone is receiving some phenomena, one thing he needs to know is he is observing people around him.
These people do not necessarily own a fixed property for him to study. They are people who are developing. A person can be either good or bad.

Second, people have to understand the effectiveness of political generics. Almost all the governments in the world want to use generics to create a divide, stirring up the desires and emotions of the masses. When this happens, people need to realize the phenomena they receive are chosen by the government, therefore, the generics the government convey do not have the authority to guide people's life and control their behaviors.

\section{CONCLUSION}

As we can see clearly above, people still need to deeply discuss what truly makes generics be generics. Only when people truly understand the principles of this process can we eliminate prejudice. By clearly questioning the belief in the law of existence, the belief in the law of perdurability and universality and the belief in human's ability to analyze phenomena, it's possible for people to only observe phenomena and describe phenomena instead of creating new generics. Governments understand the effectiveness of generics, using them to control their people. Nonetheless, if people can understand how language has effects on people's thinking and behavior, it will be difficult for governments to control people's minds. All the political tools can not be useful if everyone can realize generics' negative effects. Politics must use language. By studying linguistics, the researcher believes people in the future can gain their true liberty. Using philosophy to find out the lie behind propaganda and the true value of being a human is the true purpose of studying philosophy.

\section{ACKNOWLEDGMENT}

It took nearly two months for me to finish this paper. In the process of writing this paper, I encountered numerous difficulties and obstacles. Luckily, with the help of my teachers I finally finished it. In particular, I would like to express my strong gratitude to my thesis adviser, professor and teaching assistant. Thanks to professor Justin Khoo from MIT. It was him who taught me what linguistics is and how to make an analysis to current linguistic phenomenon. Without him, I would not start to write this paper. Thanks to teaching assistant Delin Deng, she played a huge role in my literature search. Thanks to my thesis advisor Ms Yufan Huang, for her selfless guidance and help, taking the trouble to help me modify and improve this thesis.

Thanks to all the scholars involved in this paper. This paper cites the research literature pf several scholars. Without the help and inspiration of their research results, I would have been difficult to complete the writing of this paper. 


\section{REFERENCES}

[1] Leslie, S. J. (2010). Generics and the structure of the mind. Philosophical Perspectives, 21(1), 375-403.

[2] Leslie, S. J. (2014). Carving Up the Social World with Generics.In:Tania, L., Joshua, K., Shaun, N.(Eds.),Oxford Studies in Experimental philosophy Volume 1 , chapter 8 .

[3] Sartre,J.P., Zhou, XL, Tang Y,K.2008 Existentialism is a kind of humanitarianism. Shanghai Century Publishing House

[4] Haslanger, S.(2011). Ideology, Generics, and Common Ground.

[5] Lyotard, J. F. F. (1984). E postmodern condition: a report on knowledge. U of Minnesota Press.

[6] Qingping Liu. Film and Political Propaganda in Germany during Nazi Rule.Dissertation,Hunan Normal University.

[7] Prasada, S. , Khemlani, S. , Leslie, S. J. , \& Glucksberg, S. . (2013). Conceptual distinctions amongst generics. Cognition, 126(3), 405-422.

[8] Leslie, S. J. . (2012). Generics articulate default generalizations. Recherches linguistiques de Vincennes(1), 25-44.

[9]Sterken, \& Katharine, R. . (2016). Generics, covert structure and logical form. Mind \& Language, 31(5), 503-529.

[10] Rooij, R. V. , \& Schulz, K. . (2019). Generics and typicality: a bounded rationality approach. Linguistics and Philosophy(41), 1-35. 